\title{
Relación puerto-ciudad, diseños alternativos al plan maestro de Empresa Portuaria de Valparaíso
}

Port-City relation, alternative designs to master plan from the Portuary Enterprise of Valparaíso

\section{Boris Ivelic Kusanovic*}

Alejandro Miranda Zúñiga**

Jorge Pastene Beitya*

Carolina Chávez Gatica*

Pablo Vásquez Chávez***

\section{Resumen}

La Empresa Portuaria de Valparaíso (EPV) inició el año 2004 el planteo del Plan Maestro de expansión portuaria para el litoral, el que cerraría definitivamente el mar para la ciudad, poniendo en peligro la condición de Patrimonio Mundial de la Humanidad. Los diseños alternativos pretenden equilibrar y evitar conflictos entre la expansión portuaria y la destinación de espacio público y patrimonial del borde costero. El objetivo del trabajo es poner en discusión las propuestas alternativas al plan maestro para el puerto de Valparaíso de EPV. Para ello, se analizan tres conceptos clave: la relación puerto-ciudad; el "maritorio urbano", que considera la relación habitable de mar y territorio; y el rol del diseño urbano-marítimo en operativizar los dos anteriores, resguardando el destino de Valparaíso.

\begin{abstract}
The Empresa Portuaria de Valparaiso (EPV), Valparaiso's Port Company, in 2004 initiated the master plan for the port expansion. A plan that would definitely separate the sea and the city; putting in danger a World Heritage Site. Alternative designs pretend to balance and avoid conflicts between the port expansion and public heritage space destination of the coastal border. This paper discusses alternative propositions to the master plan for the Port of Valparaíso, offering through three base concepts: the port-city relation; the habitable relation between territory and sea; and the role of urbanmaritime design to protect Valparaiso's future.
\end{abstract}

Keywords: port, urban design, Valparaíso.

Palabras clave: diseño urbano, puerto, Valparaíso.

\footnotetext{
* Escuela de Arquitectura y Diseño, Pontificia Universidad Católica de Chile, Valparaíso, Chile. Contacto: boris.ivelic@ead.cl

** Arquitecto, Universidad de Valparaíso.

*** Arquitecto, Pontificia Universidad Católica de Valparaíso.

Cómo citar: Ivelic, B., Miranda, A., Pastene, J., Chávez, C., y Vásquez, P. (2017). Relación puerto-ciudad, diseños alternativos al plan maestro de Empresa Portuaria de Valparaíso. Revista de Urbanismo, 36, 97-113. http://dx.doi.org/10.5354/0717$\underline{5051.2017 .45175}$
} 


\section{Introducción}

Antes de que se creara EPV en 1998, la empresa portuaria de Chile (Emporchi), encargó a una consultora italiana ubicar en la Región de Valparaíso un nuevo puerto. El lugar elegido fue la desembocadura del río Aconcagua, en Concón, como el único lugar resguardado y que contaba con las condiciones para construir un puerto moderno. En 2011 se tomó este desafío iniciándose el estudio del puerto alternativo al que llamamos "Parque Puerto Aconcagua", respetando la condición de humedal y la tendencia de abrir los puertos a la ciudad.

Unesco, en febrero de 2014, planteó serias observaciones al proyecto del Mall Barón y al proyecto de ampliación del puerto T2 por no respetar el sitio Área Histórica de la Ciudad Puerto de Valparaíso y el impacto a su valor universal excepcional (Vergara-Constela y Casellas, 2016). En ese contexto, la Presidencia de la República el 8 de agosto de 2014 nombró un comité que propusiera diseños arquitectónicos alternativos y un período de audiencias para escuchar las opiniones de la ciudadanía, dentro de los plazos establecidos por Unesco. En este caso, nuestra casa de estudios presentó un diseño arquitectónico alternativo al comité, presidido por el entonces Gobernador de la Provincia de Valparaíso. El proyecto tuvo una serie de exposiciones académicas, públicas y en los medios de comunicación, sometiéndose de esta manera al debate ciudadano, tal como lo solicitaba el llamado presidencial.

En 2016 EPV hizo un llamado a las universidades de la Región de Valparaíso para proponer estudios y proyectos que mitigaran y compensaran los problemas que podría ocasionar a la ciudad el proyecto T2 de ampliación del puerto. En esta ocasión no participamos, pues los conceptos de mitigación y compensación aluden a atenuar o suavizar algo negativo, dar un beneficio como reparación de un daño, perjuicio o molestia causado. El proyecto tiene serias carencias con la ciudad, para nosotros uno de los más importantes es que el T2 atenta contra el destino de Valparaíso, al perder definitivamente el borde costero y el mar, su principal patrimonio ciudadano.

El proyecto alternativo propuesto entonces, considera que "Si la gestión es consentida por todos en función del espacio público, induce a grandes transformaciones sociales y de estas dependen el éxito de los proyectos" (Mashini, 2012, p. 1). Se quiere equilibrar los intereses del crecimiento portuario con el desarrollo urbano del Gran Valparaíso, acorde con el paisaje arquitectónico de la ciudad, sumado a que es un proyecto que fue debatido y sometido al consenso ciudadano.

Los objetivos específicos de la propuesta de diseño urbano marítimo son:

- Parque puerto Aconcagua. Ubicar el Terminal portuario a gran escala propuesto por EPV en Yolanda, en la caja de la boca del Río Aconcagua, en Concón, dejando libre el sector norte del borde costero de Valparaíso.

- Parque de mar Puerto Barón. El Mall Barón, reemplazarlo por un parque urbano marítimo (maritorio), con un canal de navegación de aguas calmas, playas, marinas y terminal de cruceros.

- Parque Puerto Valparaíso. Desplazar la ampliación del puerto T2 a la poza de abrigo, protegido por el molo, conservando el mismo programa y capacidad del T2, para constituir el Espigón Prat, prolongando el Parque Barón, el canal y creando una barrera antitemporales.

- Estaciones intermodales. Soterrar las vías de circulación terrestres de avenida Errázuriz y constituir estaciones intermodales para el metro, la locomoción colectiva, los taxis fluviales y los teleféricos, conectando el mar, el plan y los cerros en forma transversal y longitudinalmente, liberando la superficie para el programa del parque.

El presente trabajo plantea como hipótesis que solo abriendo el borde costero la ciudad de Valparaíso podrá salir de su crisis, en tanto que el plan maestro de EPV terminará por hundir esta posibilidad.

Valparaíso, como todos los puertos del Pacífico, se sitúa en un mar abierto y desprotegido. El molo de abrigo fue una obra descomunal, pero insuficiente: no se puede desafiar al mar con obras ciclópeas, sino haciendo entrar el mar a la tierra, en el concepto de "maritorio", esto es, unión de agua calma y tierra, volviendo habitable el mar.

\section{Marco teórico conceptual}

\section{Proyecto alternativo al terminal a Gran escala de Yolanda}

Hoy el crecimiento de un puerto se da abriendo otro puerto, en otro lugar. Los nuevos puertos en el mundo son inmensos, no los puede albergar una ciudad. El crecimiento de los buques es exponencial, hoy hasta 18.000 TEU, de capacidad de transporte en embarcaciones triple $\mathrm{E}$, de $400 \mathrm{~m}$ de eslora, que bajan el costo de los fletes. Los puertos modernos son totalmente 
automatizados, con reserva de espacio para crecer, con fluidas conexiones viales y de ferrocarril, sin pasar por ciudades. Los puertos en Chile se generan por iniciativa privada, sin planificación estatal ni particular. Para nuevos terminales, rige la ley de la oferta y la demanda. Frente a esta carencia de planificación, el presente estudio propone un nuevo puerto a gran escala.

Puertos a gran escala. Los principales puertos del tempestuoso mar del norte están ubicados en las cuencas protegidas de ríos. Es el caso de los puertos del mar del norte, como Rotterdam en Holanda, Amberes en Bélgica y Hamburgo en Alemania, ubicados al interior de los ríos Mosa, Escalda y Elba, respectivamente. La propuesta es evitar fundar desde las profundidades del océano, con costos enormes y no siempre con resultados auspiciosos, sino hacerlo en cuencas de amplias dimensiones, con posibilidades de crecimiento y protegidas, sin perturbar espacios urbanos. Por ejemplo, en el caso del puerto de Rotterdam, que tiene una extensión de $8 \mathrm{~km}$, se han construido canales paralelos al río, albergando nuevos sitios de atraque. En la actualidad dicho puerto tiene $40 \mathrm{~km}$ de canal portuario.

Esto muestra que es importante la existencia de grandes puertos tanto en el eje Atlántico como en el eje Pacífico. En el Atlántico están Brasil, Argentina, Uruguay y, hacia el Pacífico, los puertos del sudeste asiático, puntos claves de relaciones comerciales nacionales e internacionales. En la actualidad los países con mayor desarrollo están en Asia, por lo cual el nuevo escenario comercial es la Cuenca del Pacífico.

\section{Parque Puerto Aconcagua}

En nuestro caso, proponemos como el sitio ideal la desembocadura del río Aconcagua, por tratarse de una cuenca protegida. El eje del Aconcagua incluye el Pacífico-Atlántico y también el de sus accesos, además, cuenta con aeropuerto, ferrocarril y zonas interiores para puerto seco.

Este sería el primer Parque Puerto en Chile, ubicado en una cuenca fluvial y con el calado necesario para buques de alta generación (Pospanamax Plus y Post neopanamax), esto es, embarcaciones que pueden acceder por las nuevas esclusas del canal de Panamá.

Al respecto, existen dos ejemplos extraordinarios de capacidad de gestión y valor por parte de sus impulsores: el exalcalde de Guayaquil, León Fabres Cordero, y el secretario de transporte Frank Salbucci, de EE.UU. en Guayaquil. 


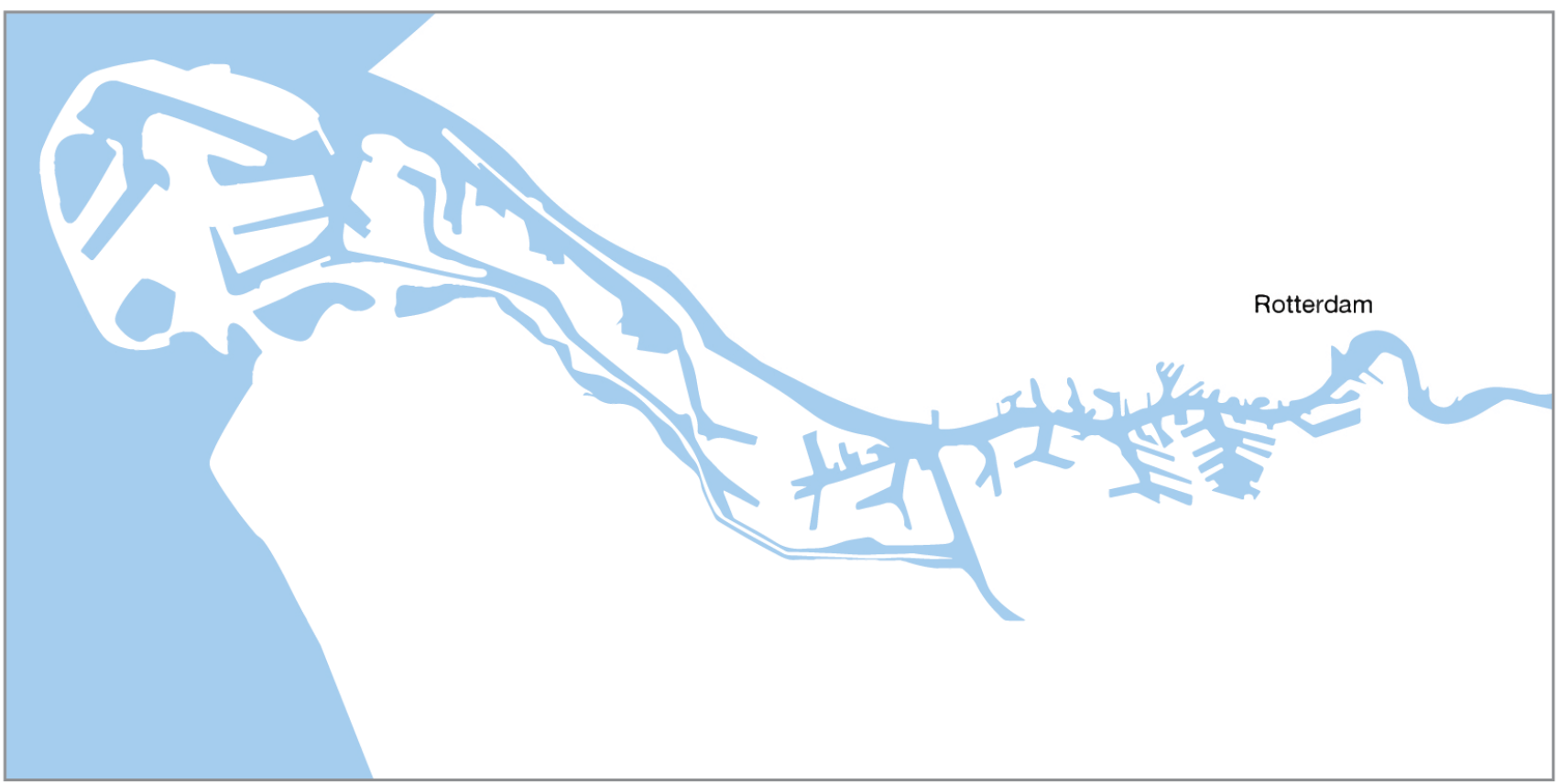

a

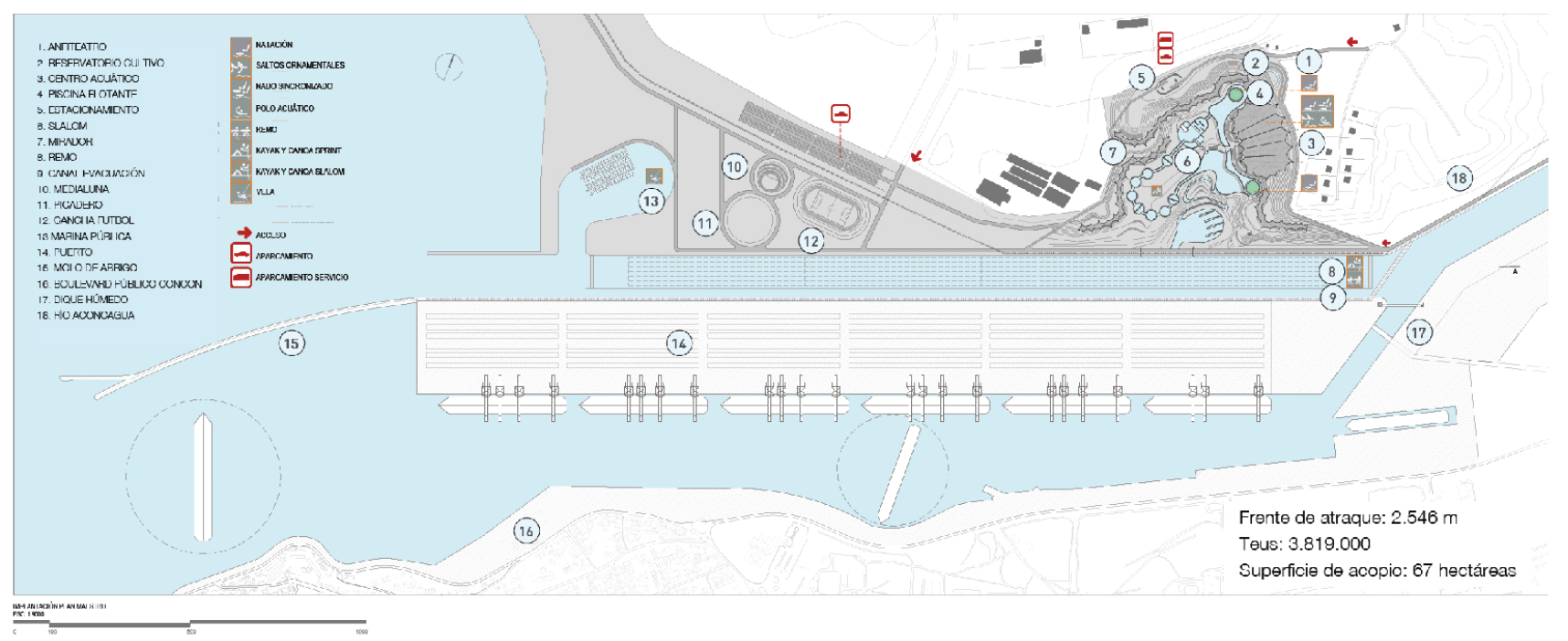

b

Figura 1 (a): Esquema del Puerto de Rotterdam, ubicado en el interior protegido del Río Mosa. En caso de tempestad se cierra una enorme compuerta en su boca. Fuente: Elaboración propia 2014. Figura (b): Plano General del Parque Puerto Aconcagua. Fuente: Deney (2011); Figueroa (2010); Soza (2010); Torrez (2013).

Malecón 2000. Obra de remodelación del borde costero del río Guayas, donde la Municipalidad de Guayaquil constituyó una fundación sin fines de lucro, para planificar, desarrollar, construir, administrar, financiar y mantener el malecón. Declarado espacio público saludable por la Organización Panamericana de la
Salud (HOP) y la Organización Mundial de la Salud (OMS). Esta obra financiada con aportes de sus ciudadanos ha ido generando ganancias anuales producto de arriendos y flujo turístico, las que han permitido ir renovando la ciudad en zonas deterioradas, con obras para el espacio público (Mashini, 2012). 
Boston, EE.UU. En la década de los 50, ante los problemas de congestión vehicular, se construyó una de las primeras autopistas elevadas en el mundo. Con el devenir del tiempo la autopista se deterioró, cortando a la ciudad en dos y separándola del mar, con lo cual se acumulaba la congestión, crecía la contaminación de gases y los ruidos del tráfico se volvieron insoportables. En la década de los 90 se propuso un cambio revolucionario: "hay que demoler los errores urbanos", lo cual implicaba reemplazar la autopista elevada por autopistas subterráneas. En un prodigio de ingeniería, se construyeron los túneles bajo las autopistas, sin detener el tráfico. Luego se demolieron las autopistas elevadas y se convirtieron en parques. Como resultado de ello la ciudad se transformó al recuperar el mar y nuevas áreas verdes. El costo de las obras superó largamente el presupuesto inicial, con gran escándalo de algunas autoridades y ciudadanos, sin embargo, después de diez años de construidas las obras, se ha logrado recuperar la inversión, gracias al aumento del flujo turístico en una ciudad renovada y a la eficiencia de las circulaciones, evitando tacos, demoras y ahorro energético (Mega Structures Boston Big Dig, 2016).

\section{Metodología: espiral de diseño y modelos físicos}

La espiral de diseño es una metodología teórica empleada en el diseño naval y marítimo, que especifica e integra todos los requerimientos de alto nivel (RAN) para cumplir con los objetivos del proyecto a través del diseño urbano-marítimo.

Para llevarla a cabo se trabaja en el campo de los fluidos, cuyo comportamiento físico es similar en líquidos y gases. El comportamiento estático de los líquidos puede ser abordado teóricamente con fórmulas matemáticas, pero no ocurre lo mismo con el comportamiento hidrodinámico. Los ingenieros acceden por medio de modelos digitales, cuyo programa se basa en datos estadísticos, los cuales se emplean como hipótesis para realizar modelos análogos que serán verificados en túneles de viento (para el diseño aerodinámico) y canales de prueba para el diseño hidrodinámico del modelo.

\section{Modelos físicos}

Para diseñar las obras urbano-marítimo realizamos modelos físicos del proyecto a escalas geométricas, cinemáticas y dinámicas, aplicando el método del "análisis dimensional y la semejanza dinámica", asimismo los números adimensionales de Reynolds y Froude para fluidos. Mediante ensayos de laboratorio en una plataforma marítima y un canal de olas, se verifica el funcionamiento del modelo, cualificándolo y cuantificándolo. Si el resultado no es el esperado, se procede a corregir y ajustar el modelo aplicando prueba y error por pasos sucesivos, hasta llegar a los resultados programados.

El laboratorio y el modelo es el equivalente a la antigua mesa de dibujo, donde se va diseñando y al mismo tiempo verificando su comportamiento.

Los modelos análogos permiten visualizar los fenómenos hidrodinámicos en toda su complejidad, sobre todo cuando se innova en la forma, experiencia irremplazable para arquitectos y diseñadores, que trabajan en la tridimensionalidad del espacio. Técnicamente el proyecto se fundamenta en base al desarrollo de un trabajo multidisciplinario que incluye arquitectos, ingenieros marítimos, civiles hidráulicos, arquitectos navales, oceanógrafos y diseñadores, además de pruebas con modelos en laboratorio. Estos procedimientos permitirían fundamentar técnicamente la factibilidad del puerto propuesto, así como también incorporar el agua como un elemento arquitectónico y urbano para el espacio público de la ciudad.

\section{Análisis crítico al proyecto de expansión del T2 de Valparaíso}

Los puertos en Chile están ubicados frente al Pacífico abierto y desprotegidos de los temporales norte, al igual que los del resto de Sudamérica. El único puerto protegido naturalmente es el de Ecuador, ubicado al interior del río Guayas.

El puerto de Valparaíso, en ese sentido, presenta dificultades para quienes recalan aquí, ya que en caso de temporales las embarcaciones deben salir a capear fuera de la bahía, con los consiguientes peligros ya conocidos de corte de amarras, quedar a la deriva y varar en la costa: el puerto es un cementerio de barcos.

La primera duda técnica que emerge frente a esta realidad es que el molo resguarda al T2 solo en un $50 \%$, mientras que el otro $50 \%$ está en aguas abiertas y no se contempla ampliar la poza de abrigo.

En segundo lugar, la carga y descarga de los buques Panamax utilizan la tecnología de las grúas-pórticos que requieren una dársena, lo cual implica contar con un mar completamente protegido de olas y viento. El operador debe calzar con la grúa los cuatro orificios de las esquinas del contenedor, a 30 o $45 \mathrm{~m}$ de altura. Además, el T2 contempla el atraque de los barcos en forma paralela al muelle, lo que implica exponerlos al oleaje y a la posición más sensible de un barco, esto es, de babor a estribor. 
En tercer término, el Acceso Sur está saturado con un flujo de camiones cada 45 segundos y según contrato con el terminal del Pacífico y EPV es de uso exclusivo para ese terminal. Sin embargo, el atraque de un Pospanamax implica descargar en 24 horas, lo cual implicaría una frecuencia de un camión cada cinco o diez segundos, los que estarían circulando por la Avenida Argentina. En este escenario no habría otra solución que construir un segundo túnel por el Acceso Sur, lo que desde la misma EPV aseguran que existiría una congestión en este acceso, debido al aumento de operaciones que demandaría el T2.

En cuarto lugar, el relleno para instalar el terminal implica una enorme extracción de tierra y rocas, lo que conlleva la destrucción del ecosistema de las áreas que se intervenga. Dadas las protestas de sus habitantes, la propuesta inicialmente instalada en Laguna Verde, luego debió trasladarse al Fundo Los Perales, en el camino La Pólvora. Esta acción impactará en la reposición de su flora y fauna, además de congestionar el acceso al puerto con 131 mil viajes de camiones trasladando los áridos.

Técnicamente no se entiende el relleno, ya que es una plataforma sobre pilares, lo que induce a pensar que si no es por el negocio portuario, podría ser por el negocio inmobiliario y pasaría a ser el borde costero de exclusión territorial y elitista (Etulain, 2008; Mansilla Quiñones y Fuenzalida, 2010). Asimismo Janoschka (2002) plantea que el abandono de la gestión urbana por parte del Estado, implica formas urbanas comercializables por actores privados, como los centros comerciales, los que desvirtúan los verdaderos proyectos urbanos que requiere la ciudad.

\section{Estudio de modelo en canal de pruebas de España, encargo de $\operatorname{TCVAL}^{1}$}

Estudio experimental de la operatividad en el nuevo terminal número 2 del Puerto de Valparaíso, Chile. Ensayo de buque atracado ${ }^{2}$.

Principales conclusiones del estudio ${ }^{3}$ :

- “...períodos iguales o inferiores a $12 \mathrm{seg}$. No ha provocado, en general problemas de operatividad.."

- “..se resiente sensiblemente con oleajes de períodos de 16 seg..."

\footnotetext{
${ }^{1}$ TCVAL: Terminal Cerros de Valparaíso, Concesionaria del T2.

${ }^{2}$ Realizado por el Instituto de Hidrodinámica Aplicada, Ronda Can Fatjó no 8, Cerdanyola del Vallès, 08290. España. (1)(eripolld@inha.com.es) (frodriguezp@inha.com.es) (dmoreno@tcval.cl)

${ }^{3}$ Antecedentes obtenidos del VII Seminario Internacional de Ingeniería y Operación Portuaria SIOP. San Antonio, Chile 2016.
}

- “..se destaca la evidente mayor operatividad del atraque No 9 con respecto al No 10 por tratarse de una zona de atraque más resguardada.."

Tomando los datos estadísticos de oleaje de la bahía de Valparaíso ${ }^{4}$ nuestros ingenieros concluyen en lo siguiente:

\begin{tabular}{lll}
\hline Período de $12 \mathrm{~s}$ & El 30\% del tiempo & Operativo 109 días \\
\hline $\begin{array}{l}\text { Períodos entre } 13 \\
\text { y } 15 \mathrm{~s}\end{array}$ & El 71\% del tiempo & Incierto 224 días \\
\hline Períodos de 16 s & El 8,4\% del tiempo & $\begin{array}{l}\text { No operativo 14.6 } \\
\text { días }\end{array}$ \\
\hline
\end{tabular}

Un puerto moderno no puede operar con incertidumbre, sino con certezas. Por ello los puertos modernos operan en dársenas.

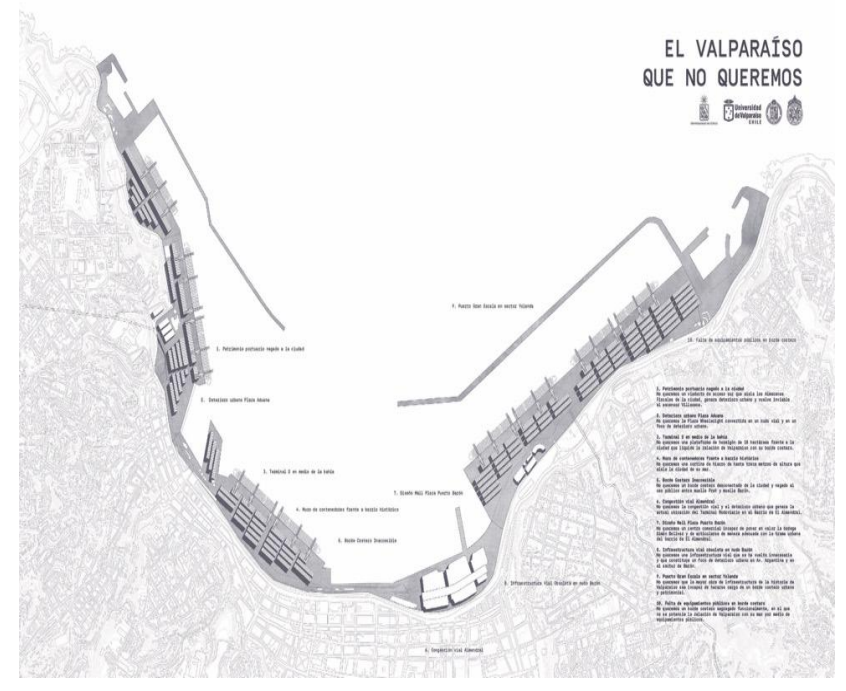

Figura 2: El Valparaíso que no queremos.

Fuente: XIX Bienal de Arquitectura, varios autores, 2014.

\section{Relación puerto-ciudad}

En 1954 a través de un proyecto urbano en Achupallas, Alberto Cruz planteaba que "Valparaíso ha perdido el mar y por tanto su Destino Marítimo" (Cruz, 1954). Hoy, a 63 años de esta afirmación y con los planes de expansión de EPV, Valparaíso desaprovecharía definitivamente la posibilidad de recuperar su litoral.

\footnotetext{
${ }^{4}$ Datos obtenidos de: Estimación del Clima de oleaje en la V Región, Consideraciones de diseño. Instituto Nacional de Hidráulica.
} 
Tanto los cerros como el plan de Valparaíso perdieron el mar debido a los obstáculos de sus vías y porque el puerto, en la década de los 70, cerró el borde costero, incluso en aquellos lugares que hoy no son utilizados y están en abandono.

Valparaíso: su borde marítimo en crisis. Hoy el borde marítimo de Valparaíso es un sector postindustrial abandonado, donde el mar ha quedado oculto a los ojos de sus habitantes, se trata de un lugar desvalorizado, en el que tampoco se le ha dado vida a través de oficios como la pesca o el turismo. El mar está contaminado, sin playas habitables, ni espacios públicos de encuentro de sus habitantes. La ciudad solo tiene $0,5 \mathrm{~m}^{2}$ de áreas verdes por habitante. El promedio recomendado por OCDE es de $9 \mathrm{~m}^{2}$ por habitante, Viña del Mar y Vitacura tienen $12 \mathrm{~m}^{2}$, Santiago tiene $10 \mathrm{~m}^{2}$.

"El Océano Pacífico es para América una carencia" (Cruz y lommi, 1970). Carencia entendida como falta de visión oceánica y que afecta a 12 naciones de América Latina.

Chile no es ajeno a esta carencia y en la ciudad de Valparaíso esto se evidencia en cada temporal que destruye parte del litoral, ante catástrofes que se repiten cíclicamente, así como también en cada proyecto que no considera la condición habitable del mar o maritorio, como ocurre con el proyecto del Mall, del terminal T2 y del proyecto a gran escala propuesto en Yolanda.

Es por eso que la expansión del puerto implica desconocer este espacio propio de una ciudad costera. Ello, repetimos, implicaría la pérdida definitiva de recuperación de este bien patrimonial que es de todos sus habitantes. La ciudad de Valparaíso no resistiría esta acción invasiva, no solo en el borde costero, sino tampoco en las vías de acceso. El urbanista Ignacio Santa María plantea al respecto: “(...) Ilegar a ser una nación oceánica como condición necesaria para construirnos un destino propio y trascendente, en la era y en la cuenca del Pacífico" (Santa María, 1988).

Abrir el borde costero. Tomando ejemplos del Gran Valparaíso, comunas como Viña, Reñaca y Concón, han tenido un auge debido a que presentan un frente litoral abierto y público que dinamiza su desarrollo social y económico, de allí que la presente investigación proponga la apertura del frente costero de Valparaíso, para salir así de su actual crisis a través de la incorporación del concepto de maritorio.

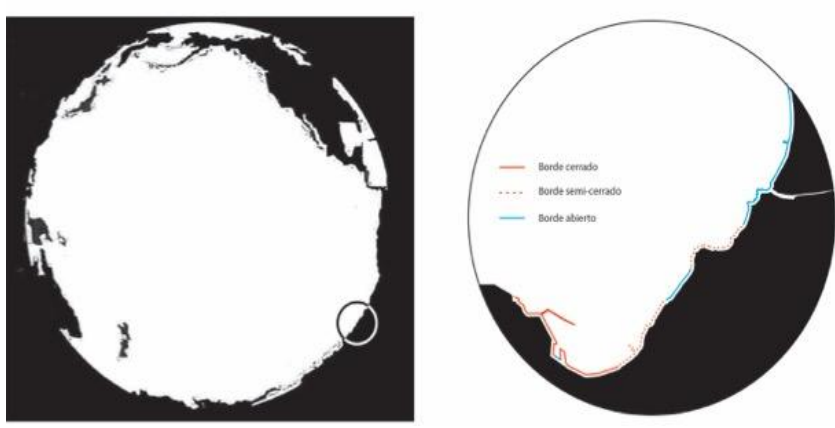

Figura 3 (izquierda): El Pacífico ocupa prácticamente la mitad del Globo terráqueo. Fuente: Cruz y lommi, 1970. Figura (derecha): Valparaíso ubicado frente al Pacífico con su frente litoral cerrado. Fuente: elaboración propia, 2016.

La abertura de los puertos internacionales a la ciudad. Las ciudades-puerto en el mundo han comprendido la influencia que ejercen en el borde costero urbano y se han abierto a ella, derribando sus muros. Así mismo, la invención de los contenedores revolucionó los puertos, cambió los procedimientos de carga y descarga, se agilizó el proceso y evitó los almacenes de rezago, dejando solo espacios abiertos momentáneos de almacenamientos de contenedores.

Barcelona, por ejemplo, abrió su puerto a la ciudad con motivo de los Juegos Olímpicos de 1992. Los urbanistas y arquitectos plantearon que una ciudad portuaria no podía tener el mar detrás de un muro. La remodelación empezó por su borde costero. Hoy el puerto tiene marinas, playas, restaurantes, comercio de alto nivel y paseos y lo propio ocurrió con el puerto de Génova, el puerto de Rotterdam y muchos otros ejemplos.

\section{El concepto de maritorio}

El estado del arte respecto de las políticas de borde costero señala que a nivel global se protege el borde costero como un bien común, en ese sentido no se puede construir a menos 100, 200 o 500 mts. del litoral y normalmente las autopistas van soterradas o distanciándose del mar. Es el espacio público de todos sus habitantes y a su vez de nadie.

El maritorio, en tanto, es un concepto análogo a territorio que implica hacer habitable el mar, romper el límite con la tierra como obstáculo y crear un ancho de fusión de agua y tierra. En un contexto de un Océano Pacífico abierto a temporales y tsunamis, se busca el "agua calma", no desafiando al mar, sino ingresándolo controladamente a tierra, a modo de brazos de mar (Baeza, Vial, Uribe e Ivelic, 1991). 
Además de considerar al borde costero como un bien común, se plantea el concepto de maritorio como un eje teórico clave para la comprensión y propuesta de diseño urbano para el puerto de Valparaíso. El concepto maritorio nace a propósito del texto "Maritorios de la Patagonia" (Sánchez, 1971), que concibe a la Patagonia occidental como una fusión de agua y tierra, donde los canales son el único espacio plano de dicha región, siendo equivalentes a los valles de la zona central. De esta manera, se concibe el mar como territorio para poder habitarlo, abriéndose a la posibilidad de un urbanismo de mar (Ivelic y Baixas, 1985). Lo geográfico se incorpora con sus propias características, por ejemplo, la condición de archipiélago donde el mar se interna a la tierra y la tierra se adentra al mar, creando circunstancias de protección y calma para generar fundaciones, dando cabida al arraigo, la riqueza, la circulación y la energía.

Un concepto semejante es el de maritimidad que plantean Vergara y Foulquier (2012) cuando señalan que es un espacio de diálogo entre ciudad, región y puerto para construir una maritimidad beneficiosa para todos.

Maritorios urbanos. Siguiendo esta línea argumentativa, se propone este nuevo concepto cuando grandes espacios de la ciudad incorporan el agua como elemento constitutivo de las mismas. Aguas calmas interiores, frente a mares abiertos y tempestuosos, como aquellas ciudades fundadas en archipiélagos naturales y que se internan al interior de la tierra por ríos urbanos. Ríos y archipiélagos generan espacios abiertos que permiten observan los paisajes lejanos y cercanos de la ciudad. Así mismo, los maritorios urbanos destacan las obras emblemáticas de una ciudad, pues se circula a través de ella observando con la fluidez propia del agua, sin semáforos ni tacos, casi en silencio.

Existen ejemplos internacionales que podríamos mencionar como maritorios urbanos, los cuales lograron asumir urbanísticamente las bondades del agua. En el caso de Helsinki, Finlandia, por ejemplo, los barcos se internan por la ciudad hasta la plaza principal, en tanto en Copenhague, Dinamarca, los bulevares junto a los canales conviven con cafés y restaurantes y en la misma ciudad, el nuevo edificio de la ópera está en el canal principal, junto con la nueva biblioteca. Se celebran matrimonios en embarcaciones, circulando por la ciudad a través de canales construidos que recorren el casco histórico.

Otra experiencia que se puede observar es el río Sena, Francia, donde se trata de un parque transversal, hundido, sin ruido, con lanchas restaurantes, mientras Notre Dame aparece en plenitud en una isla. En Ámsterdam, Holanda, el casco antiguo es habitado por casas flotantes y ferias de flores, mientras que en Venecia, Italia, se circula paseando mientras los gondoleros cantan. En América del Norte encontramos los ejemplos de las ciudades de Boston y Seattle donde los buses de tour son anfibios, mientras en América del Sur, en Argentina el río Tigre posee una circulación fluvial, utilizando canales urbanos y rurales, parecido a lo que sucede en Valdivia, Chile, con lanchas taxis que recorren el río junto a los botes. 

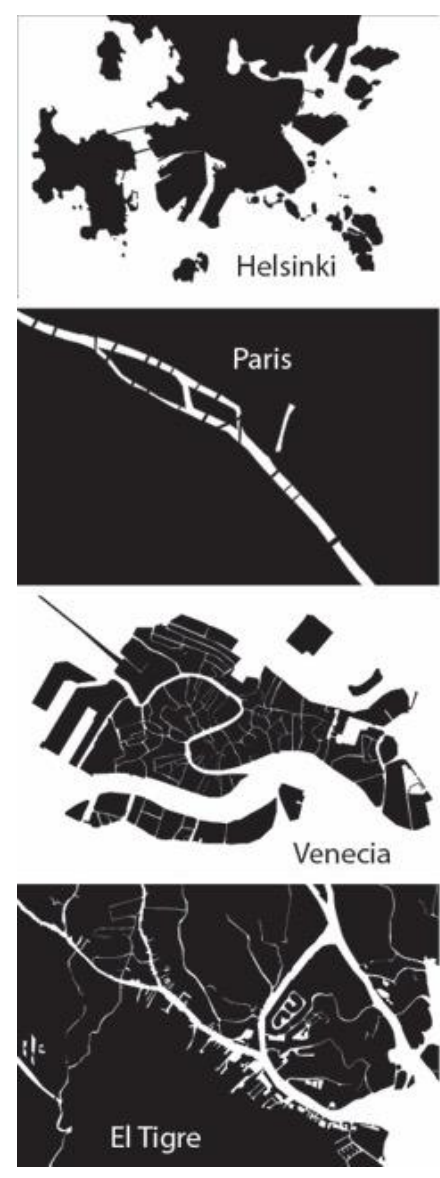

Figura 4: Los maritorios urbanos.

Fuente: Elaboración propia, 2016

Continente y contenido. Para los autores, una de las premisas de la investigación fue el llamado "continente y contenido", haciendo un símil entre tierra y agua, lo fijo y móvil. El agua toma la forma del elemento que lo contiene, con el sólido, entonces, construimos la forma del agua dando lugar a la tierra por medio de dársenas, canales, marinas, puertos, balnearios, caletas y playas, es decir, trayendo el agua hacia el interior de la tierra o la tierra a un interior protegido de agua, sin competir con el mar abierto como en el caso de Valparaíso y el Océano Pacífico.

Primer elemento urbano. La investigación propone que las obras del borde costero deben ser el primer y más importante elemento urbano de la ciudad, coexistiendo con la complejidad de requerimientos ciudadanos, sin entrar en litigio con otras obras y empresas y sin abandonar la arquitectura y el urbanismo, lo que daría cabida a todos los habitantes de Valparaíso. Como se mencionó anteriormente, el Océano Pacífico es un mar abierto y a veces violento $y$, por ende, el
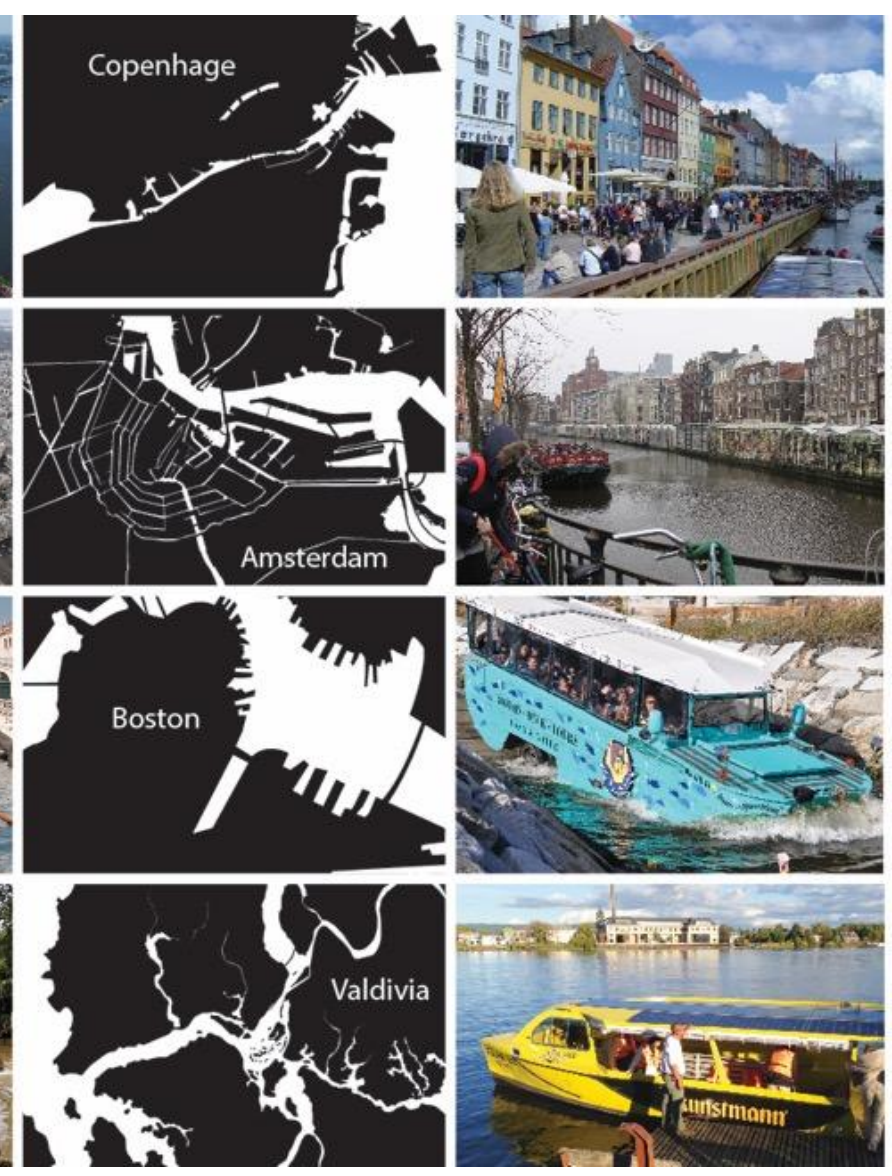

105

encuentro entre tierra y mar requiere protecciones que fijan normalmente un límite rígido -en este caso el límite entendido como obstáculo y negación de un acceso-. La investigación quiere lograr una transparencia de este límite, una abierta invitación donde se vinculen la tierra y el agua, asemejando la forma de un archipiélago.

En Puerto Montt, con el auge del salmón, el parque automotor se saturó y para aliviar la congestión, en el centro se prohibió estacionar, se construyeron estacionamientos subterráneos en el borde costero, en dos niveles, con una extensión aproximada de 800 metros. La losa de superficie quedó completamente despejada, permitiendo contemplar el mar y la cordillera de la costa nevada, generándose una gran plaza cívica para desfiles y celebraciones. Así, la ciudad se reestructuró urbanamente a partir de su borde costero.

\section{Diseño urbano-marítimo}

En este caso el diseño urbano se complementa con el marítimo, asumiendo el concepto de maritorio e involucra, por tanto, al puerto-espigón como al parque costero.

Revista de Urbanismo, 36, 97-113. 
El puerto espigón. Las instalaciones actuales del puerto y el grado de eficiencia con que opera al contar con las instalaciones de contenedores en Placilla son suficientes para satisfacer la demanda a la que es sometido actualmente.

No se justifica la opción de un puerto sacrificando el borde costero y, por tanto, la ciudad. El puerto cumplió con los requerimientos que se esperaban de él, se modernizó con las grúas pórticos y con el túnel de conexión de La Pólvora y su crecimiento ha de limitarse a la zona portuaria actual, puesto que no tiene accesos ni el espacio suficiente o adecuado para la inmensa carga que tendría que mover.

Frente a la disyuntiva actual, la investigación propone un terminal que cumpla con el mismo programa del T2, liberando el borde costero y entregándolo a la ciudad, ya que esto permitiría una profunda renovación urbana de Valparaíso, tan esperada y tan postergada. EPV se convertiría en líder ciudadano, promoviendo obras a la manera de los antiguos artífices que construyeron el rostro de Valparaíso, tales como el molo, el camino La Pólvora, el relleno del Almendral, es decir, personas con visión, coraje y amor por la ciudad.

Para lograr este objetivo sería necesario desplazar el programa y ubicación del T2 a la poza de abrigo, protegido por el molo, mediante un espigón prolongando al muelle Prat. Se trata, pues, de una plataforma sustentada sobre pilotes de acero, sin rellenos.

Por su parte, el terminal internacional marítimo de pasajeros se ubicaría en el muelle Barón, conectado al parque, en tanto que el edificio de pasajeros se ubicaría en la bodega Simón Bolívar.
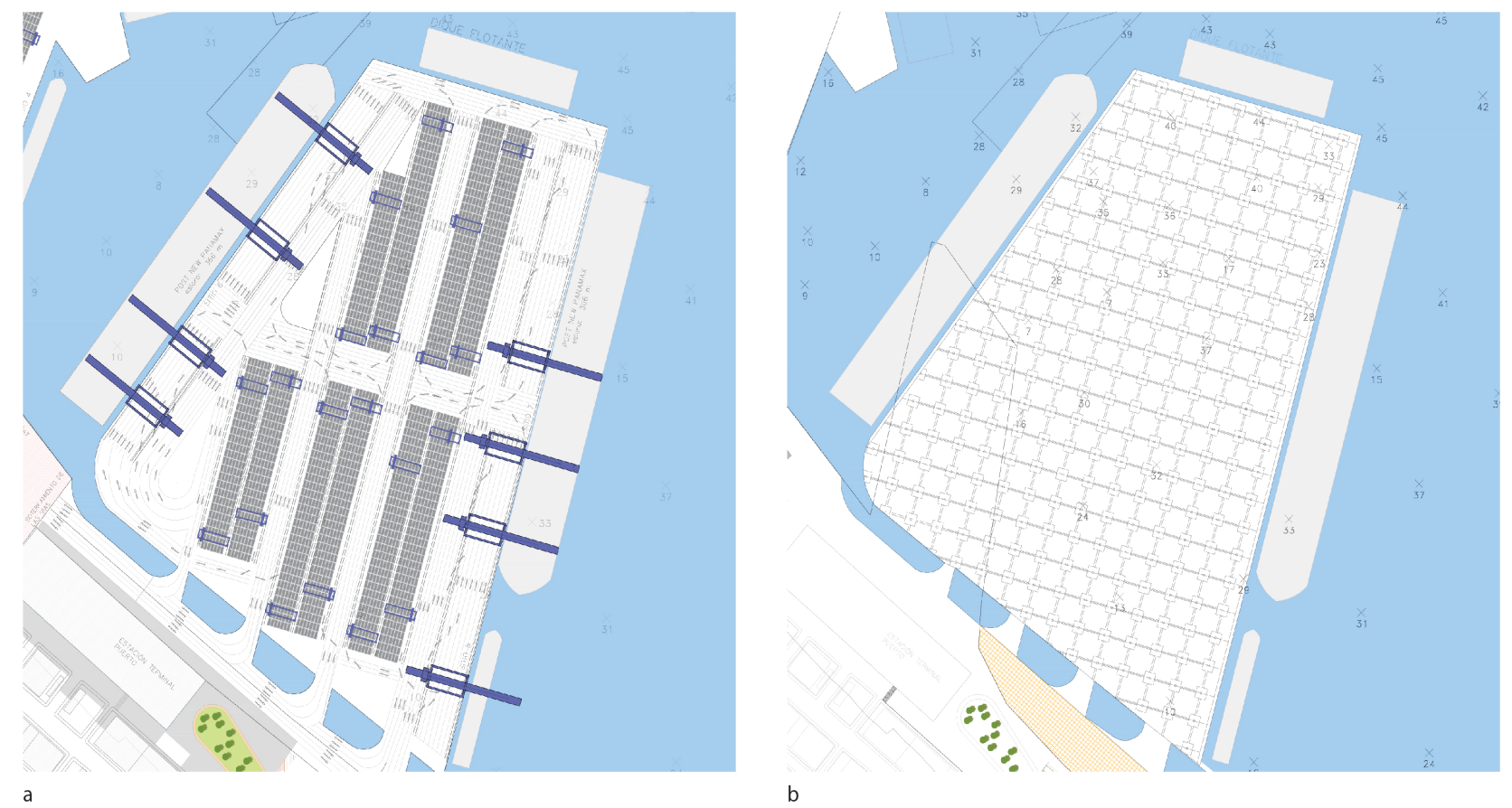

Figura 5: Plano de detalle del espigón propuesto.

Fuente: Elaboración propia 2016. 
El parque costero. Diseño que recupere el borde costero en el concepto de maritorio urbano y de aguas calmas habitables. Esto mediante la circulación a través de tres medios: tierra, agua y aire.

Circular paseando. En el proyecto de Achupallas, Alberto Cruz (1954) planteaba "Hoy la Arquitectura está en el ir, no en el estar", es decir, circular contemplando, de paseo. En la estructura vial actual esto no es posible debido a los tacos, semáforos, la densidad del parque automotor, la exasperación de los conductores, el peligro de choques que imposibilitan contemplar los espacios urbanos. Sin embargo, desde el agua esto es posible, en un canal no hay cruces, semáforos ni cuellos de botella. No es la velocidad lo importante, sino la fluidez, algo similar a lo que ocurre con los trenes de vías propias, o los teleféricos pensados para la pendiente, es decir, son escasos los lugares de la ciudad donde un automovilista puede ir de paseo y manejar lento. El borde costero que se propone incluye un canal de aguas calmas, que busca dar nuevas alternativas de circulación, junto a los teleféricos por aire.

Barrera antitemporales. Para la protección de la ciudad y las obras del parque se contempla el desarrollo de una barrera antitemporales de protección y de espectáculo de la ola. Subyace aquí la idea de no resistir los temporales en un único borde, sino generar un segundo borde, consistente en esta barrera que soporta al canal y disipa la energía de la ola. La ola es, en sí, un espectáculo que la gente va a observar, a veces con riesgo. El diseño contempla invertir la energía de la ola cambiándola de dirección, de manera que el agua, con la ayuda de unas cámaras de aire y sifones, disipe el agua en millones de gotas de agua, provocando arcos iris con la luz.

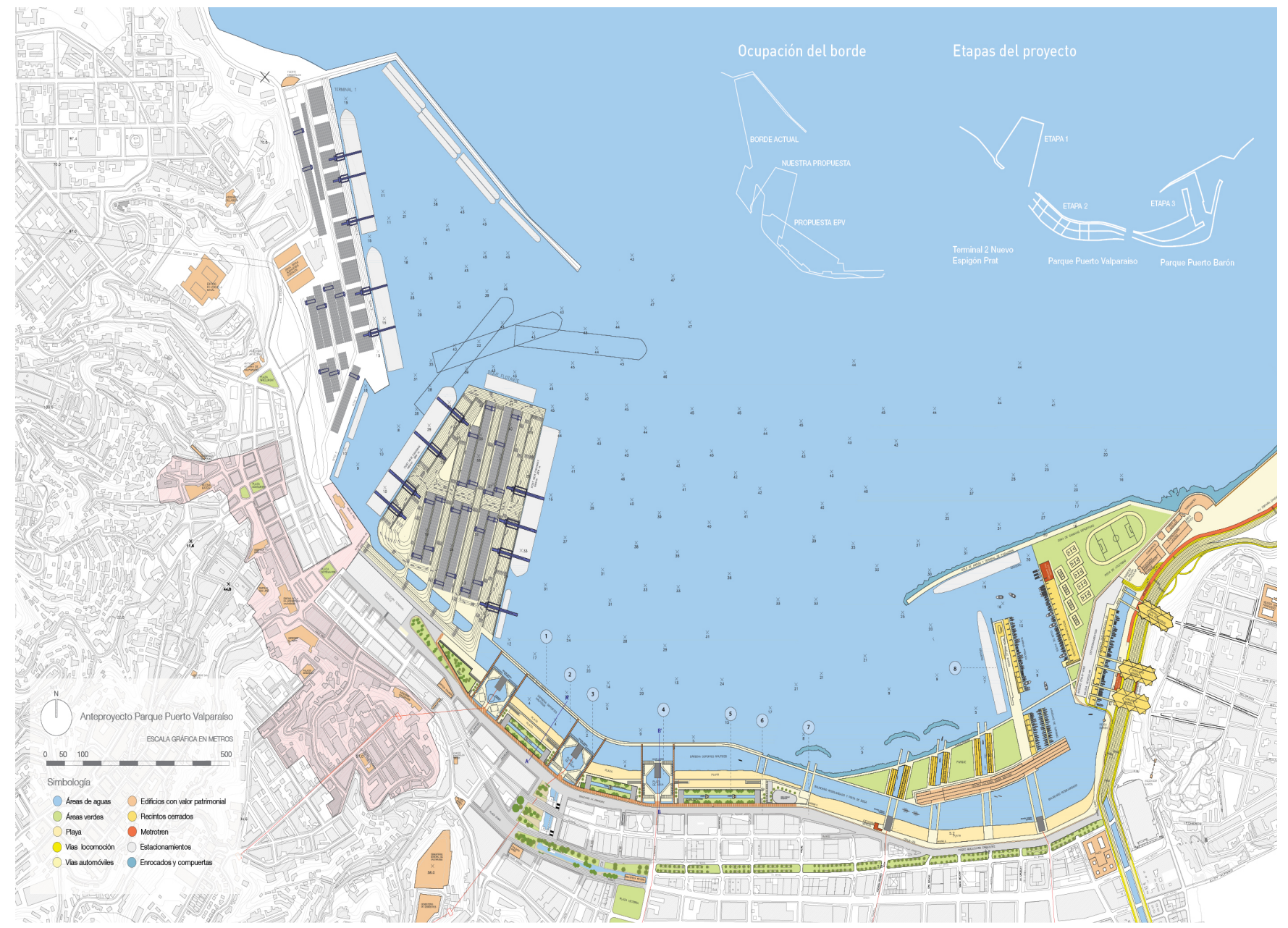

Figura 6: Plan general para el borde costero de Valparaíso.

Fuente: Vásquez, P (2015). Miranda, A. (2016)

Revista de Urbanismo, 36, 97-113. 
Teleféricos. Si se considera que la arquitectura está en el ir, se trataría de otro medio de pasear contemplando las vistas espectaculares de los cerros y la bahía. Asimismo es relevante, frente a cualquier diseño urbano, permitir los flujos que demandan los habitantes, por ejemplo, en el caso de Valparaíso descender desde los cerros al mar no es fácil, ya que la topografía, la circulación de las personas y la lentitud de los vehículos tradicionales entorpecen este objetivo. En las avenidas paralelas al mar, el tráfico vuelve peligroso al acercarse al borde costero, además de que actualmente está prácticamente cerrado y solo se contempla, el mar, paradójicamente desde los miradores a distancia y con binoculares. Sin embargo, los teleféricos hoy han conectado urbanísticamente a ciudades con los cerros como en los casos de Medellín, Colombia; La Paz, Bolivia; y Quito, Ecuador.

Soterramiento del las vías y estacionamientos bajo nivel para el parque y descongestionamiento de la zona céntrica. Esto implica recuperar la Avenida Errázuriz para el peatón, dejando de ser obstáculo y peligro para el acceso al borde costero. En la superficie a nivel de calle se podría construir un boulevard, un lugar público de paseo, desfiles cívicos, recitales, año nuevo, celebraciones.

Plazas-paraderos de aguas interiores. Se trata de un edificio plaza a cielo abierto, con un gran patio interior de aguas provenientes del canal, que permitiría conectar e intercambiar todos los niveles de circulaciones por los tres

medios.

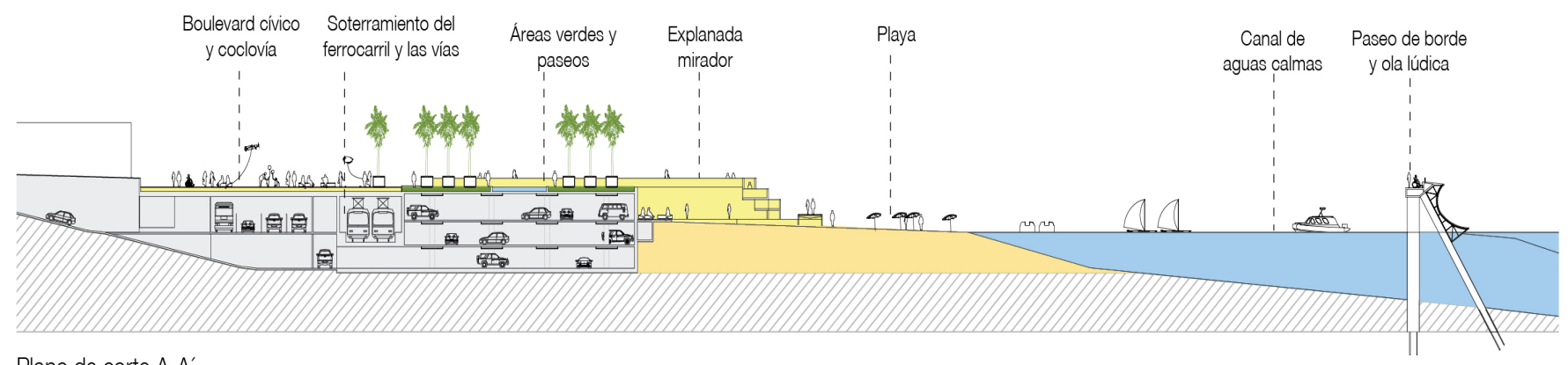

Plano de corte A-Á.
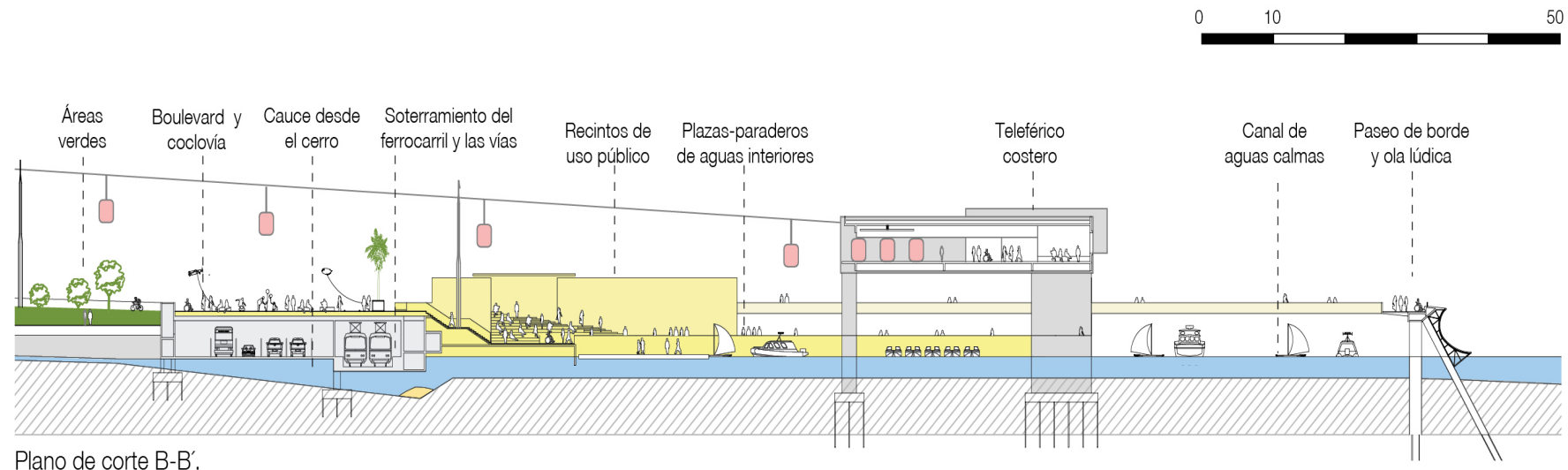

Figura 7: Cortes del Parque Puerto Valparaíso.

Fuente: Miranda, A. 2016. 

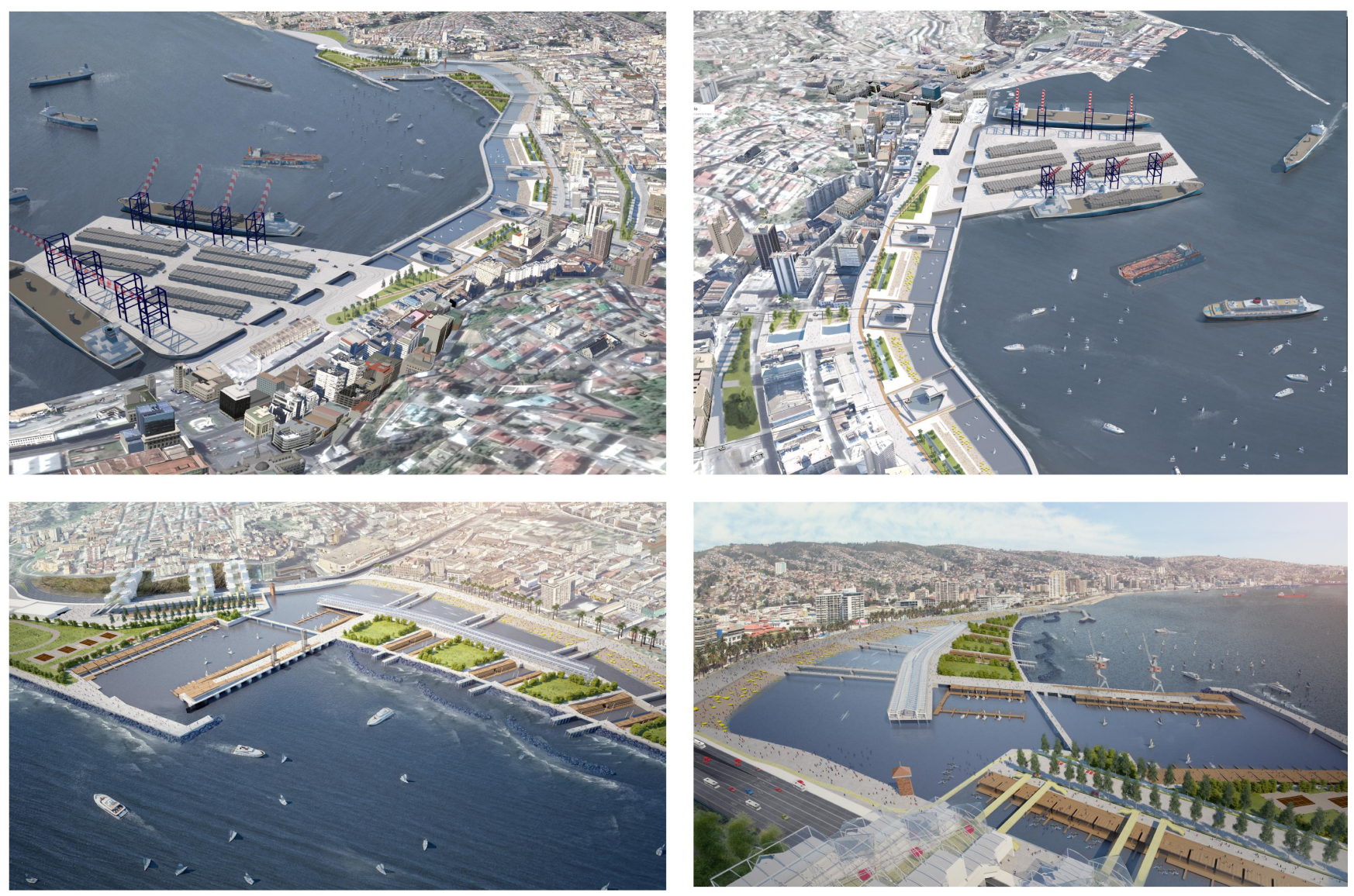

Figura 8: Perspectiva Parque Puerto Valparaíso.

Fuente: Elaboración propia, 2016.

\section{Resultados}

\section{Parque puerto Aconcagua}

Terminal portuario a gran escala, ubicado en la caja del río Aconcagua desde la desembocadura hacia el interior, con gran reserva de terrenos para su crecimiento. Se trata de un puerto fluvial interior protegido para buques de gran calado, ubicado en una isla, evitando muros y cierres de control. Allí se ubicaría el patio de acopio para 3.819 .000 teus, con una superficie de 87 ha el muelle de atraque de $2.546 \mathrm{~m}$ que puede recibir 6 barcos Neopanamax de $366 \mathrm{~m}$ de eslora.

Ante la posibilidad de embancamientos, se separan las aguas del río de las marítimas, generando dos canales paralelos con distinta dirección. Uno sur, brazo de mar y otro norte que permite la salida del río y sus sedimentos que son arrastrados en dirección norte por las corrientes. El molo se sitúa perpendicular a los temporales del norte. contribuyendo a separar los sedimentos:

El canal-sur. Portuario, abierto al mar para la entrada de los buques Pospanamax, con profundidad de $18 \mathrm{~m}$ y molo protector del oleaje norte.

Canal norte. De evacuación de las aguas del río Aconcagua, con capacidad de $3.000 \mathrm{~m}^{3} / \mathrm{s}$. de evacuación. En caso de crecidas con períodos de retorno de 500 años, se abre una compuerta en la cabecera del canal sur.

Vínculo ciudad-puerto. La ciudad de Concón se vincula al puerto por dos franjas:

- Franja costanera. Al sur, como espectáculo del puerto. Paseo de borde fluvial equipado con mobiliario urbano, juegos infantiles y restaurantes típicos.

- Franja parque-humedal. Al norte, coexistiendo el humedal y el puerto para deportes náuticos. Compuesto por una piscina olímpica y de saltos, pista de boga y canotaje de $2.000 \mathrm{~m}$ y pista de eslalom olímpico para kayak. 


\section{Parque puerto Valparaíso}

Continuidad del Parque de mar Puerto Barón, (Ivelic y Vásquez, 2014) con un canal de aguas calmas para generar una zona de mitigación, permitiendo circulaciones fluviales con lanchas taxis y deportes náuticos. El canal da cabida en su borde a $3.000 \mathrm{~m}$ de playa y baños de mar protegidos.

Barrera antitemporales. Concebida para protección de la ciudad y las obras del parque, tiene un doble propósito: contener el agua del canal interior y disipar la energía de las olas. Es una estructura basada en la defensa antihuracanes de New Orleans. Corresponde a una estructura compuesta de pilares huecos de hormigón de $1 \mathrm{~m}$ de diámetro, apuntaladas por pilares de acero en ángulos de $57^{\circ}$ y anclados mediante martinete. Una vez hincados los pilares de hormigón se procede a rellenar el interior, evitándose así grandes muros inerciales.

Disipador de olas. Una superficie curva de hormigón apoyada y estructurada en los pilares de acero, invierte la energía de las olas, cambiándola de dirección. La ola es devuelta por el disipador sin mojar la calzada.

Áreas verdes, paseos y ciclovías. Corresponde a áreas protegidas con empastadas, árboles, flores, para recibir las familias: lugares de juego, picnic, descanso, relajación. Contiene ciclovías y pistas de trote y caminata.

Paraderos intermodales de intercambio de la locomoción colectiva por agua, tierra y aire, en las intersecciones de las avenidas transversales: Metro de Valparaíso (Merval), buses interurbanos, taxis colectivos, teleféricos y lanchas fluviales.

El paradero es un edificio-plaza con un gran patio interior de agua conectado al canal y permitiendo el acceso y atraque de las lanchas taxis. El edificio-plaza cuenta con restaurantes, patio de comidas, comercio al paso, anfiteatro, sala de exposiciones, auditorio. Los niveles se conectan entre sí mediante rampas y escaleras mecánicas: nivel agua, estacionamientos, vías, calle, segundo piso y nivel teleférico.

Vías soterradas. Se sotierra el ferrocarril y las vías, dejando de ser obstáculo y peligro para el acceso al borde costero, con estacionamientos bajo nivel para el parque y descongestionamiento de la zona céntrica. Se recupera así para el peatón la Avenida Errázuriz, transformándola en un boulevard. Representaría un gran paseo público cotidiano de Valparaíso, lugar de desfiles cívicos, festividades, aniversarios ciudadanos, celebraciones, año nuevo, espectáculos musicales.
Teleférico costero, unión aérea del mar con los habitantes del cerro. Estaciones recibidoras en los cerros, ubicadas en: el casco patrimonial, en miradores, plazas, museos (a cielo abierto), Parque Cultural, Avenida Alemania.

\section{Resultados de los ensayos de laboratorio}

Parque-Puerto Aconcagua. Consistió en ensayar con un modelo marítimo y fluvial a escala, de aproximadamente $25 \times 25 \mathrm{~m}$, sometiéndolo a olas, tsunamis y máximos caudales, mediante prueba y error, lográndose los resultados antes enunciados en cuanto a superficies. El canal norte que evacúa aguas del río se diseñó para una evacuación de $3.000 \mathrm{mts}^{3}$ por segundo para períodos de retorno de 100 años. Para retornos de 1.000 años se abre la compuerta del canal-puerto con capacidad de evacuación de $6.000 \mathrm{~m}^{3} / \mathrm{s}$ El modelo se fue ajustando hasta dar con la capacidad de diseño hidráulico proyectada. El sistema constructivo para la contención del muelle es mediante geo tubos escalonados y un sistema de placa-pilar portuario.

Parque de mar Puerto Barón. Se realizó un modelo a escala 1:200, de aproximadamente $20 \times 20$ m que abarca el perímetro del parque, con la batimetría costera hasta los $45 \mathrm{~m}$ de profundidad y una extensión de $760 \mathrm{~m}$ mar adentro. Se realizaron pruebas con oleajes de $8 \mathrm{~m}$ (según estadísticas, corroboradas por temporal de 2015), y de tsunami, con altura de $4 \mathrm{~m}$ (extrapolando tsunami 27/F). El resultado fue levantar en un metro la superficie del parque. Con los rompeolas se evita que esta entre al interior de la dársena. Se probó la compuerta deslizante de la dársena para casos de tsunami, la cual funcionó, evitando que la ola entrara al interior.

Parque-puerto Valparaíso. Se ensayó la barrera antitemporales mediante un modelo a escala en el canal de olas del laboratorio, consistente en un muro curvo disipador de olas. Los ensayos preliminares no funcionaron bien según la hipótesis prevista, porque las olas no son homogéneas en su altura y frecuencia. Los ingenieros plantearon la hipótesis de añadir un terraplén rompeolas. Para ello se diseñó un modelo de plataforma sumergida, aplicando el número de Iribarren. Este es un número adimensional usado para moldear la ocurrencia de rotura del oleaje en las playas inclinadas. Se buscó producir una ola envolvente. El resultado fue una plataforma con pendiente de $15^{\circ}$. Realizados los ensayos, la ola rompió en el lugar predeterminado donde se ubicó el disipador. Al chocar la ola realiza un giro y se devuelve en dirección contraria hacia el mar. La calzada ubicada detrás del disipador permaneció completamente seca. 
Espigón Prat. Plataforma de 450 por 370 m de 17 ha, $1185 \mathrm{~m}$ de borde de atraque y capacidad de 12.432 Teus. Puede recibir dos buques Neopanamax de $366 \mathrm{~m}$ de eslora y $18 \mathrm{~m}$ de profundidad y un buque de $120 \mathrm{~m}$ de eslora. En su cabezal se recibe al dique flotante Sociber. Plataforma de losa de hormigón armado, sustentada por pilares estructurales de acero clavados al fondo marino mediante martinete. Los pilares constituyen una cuadrícula de $25 \mathrm{~m}$ y una profundidad máxima de $40 \mathrm{~m}$.

Se trata de una plataforma sin rellenos y limpia, de manera que el mar circule libremente bajo la estructura, evitando la acumulación de residuos y desperdicios. Entre el espigón y tierra (malecón) queda el canal interior de circulación. Ambos se conectan mediante puentes para la circulación de los camiones, el canal queda a cielo abierto, permitiendo visualizar y extraer los residuos que

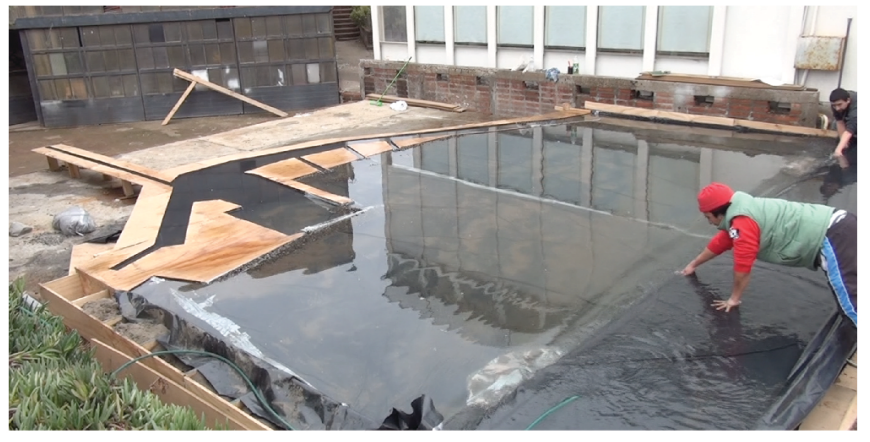

a
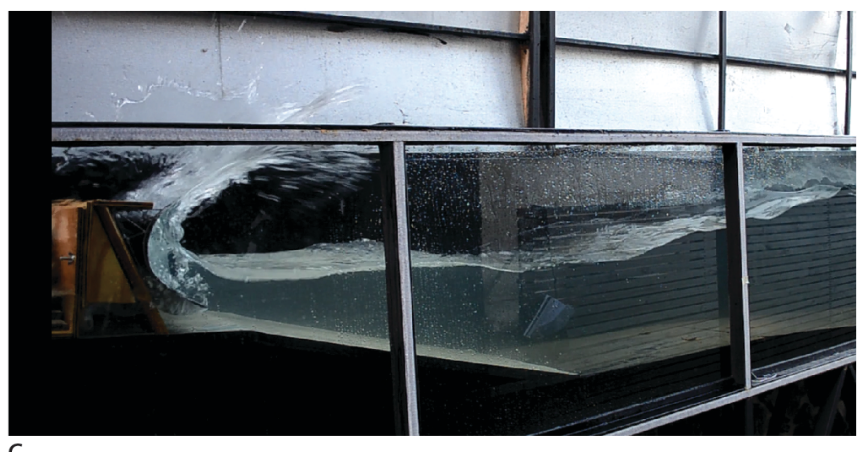

C puedan acumularse contra el malecón. El suelo marino bajo el espigón queda liberado, para permitir introspecciones que quieran realizarse del patrimonio arqueológico allí existente.

Un ejemplo de profundidades de fundación de $40 \mathrm{~m}$ es el muelle GNL de Quintero, que en su poste de amarre exterior tiene pilotes de $44 \mathrm{~m}$ de luz libre vertical (entre el fondo o lecho marino y el extremo superior). Respecto de la técnica de hinca: en Quintero se usó un Jack-up (en $42 \mathrm{~m}$ de profundidad de agua). En el espigón Prat, en aguas abrigadas, se usarían pontones de apoyo flotantes, posiblemente con dos o más equipos de hinca, grúas y torres de operación, para colocar los tubos fragmentados, soldarlos e introducirlos al mar, hasta tocar terreno de fundación.

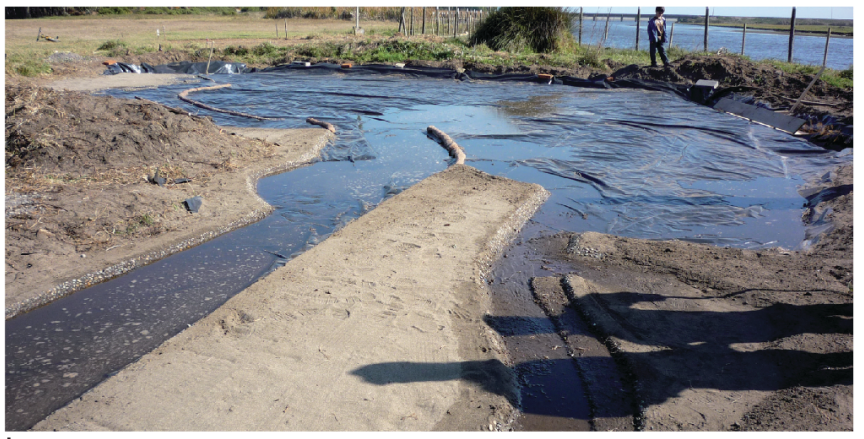

$\mathrm{b}$

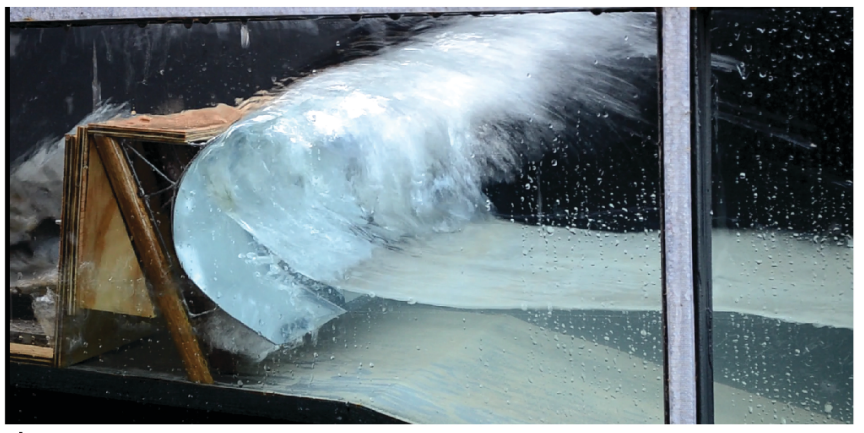

d

Figura 9a: Prueba de tsunami y oleajes, Parque de mar Puerto Barón. Fuente: Elaboración propia. 2014; Figura 9b: Pruebas de oleajes y caudales, Parque Puerto Aconcagua. Fuente: Elaboración propia, 2010. Figura 9 c y d: Pruebas de oleajes barrera anti temporales. Parque Puerto Valparaíso. Fuente: Elaboración propia, 2016.

\section{Modelo de gestión}

Tratándose de una obra de gran magnitud que transformaría Valparaíso, para la ejecución de la propuesta esbozada sería necesario un gran acuerdo entre todas las autoridades involucradas con la ciudad y el puerto, con consulta a la ciudadanía a través de un plebiscito.

Esta propuesta debiera considerarse como un plan maestro, que después de los estudios de desarrollo y de ser aprobados, tendría que convertirse en un Plan Seccional, con los cambios y destinación de usos del 
suelo, para convertirlo en ley de la República. Así mismo, se debiera planificar su ejecución en etapas, en el corto, mediano y largo plazo, con el apoyo de un comité especialmente designado para llevarlo a cabo.

El anteproyecto está pensado para que la gran inversión involucrada pueda ser financiada a través de particulares, sobre la base de licitación de concesiones: estacionamientos, teleféricos, locales comerciales, oficinas, restaurantes, anfiteatros, salas de exposiciones, marinas, balnearios, paraderos taxi lanchas, etc. La propuesta plantea las siguientes etapas:

1) Plataforma portuaria. Si bien el puerto se integra al parque, es un ítem que le corresponde administrar a EPV.

2) El Parque Puerto Valparaíso.

3) El Parque de mar Puerto Barón.

En estos dos últimos ítems debiera contemplarse la participación estatal y privada, pudiendo ejecutarse en forma separada y al mismo tiempo, o bien, en distintos tiempos, según lo ameriten los estudios de inversión y ejecución, así como también con actividades que se verifiquen en el corto, mediano y largo plazo.

\section{Conclusiones}

Cuando las ciudades crecen y los puertos no cuentan con el espacio suficiente, emigran, como los aeropuertos (Álvarez, Silva y Soto, 2009). Los principales puertos del tempestuoso mar del norte están ubicados en las cuencas protegidas de ríos: Rotterdam en Holanda, Amberes en Bélgica y Hamburgo en Alemania.

En laa propuesta aquí contenida el puerto a gran escala en la cuenca del Aconcagua respondería a los desafíos de los puertos modernos: dársena plenamente resguardada, espacio de reserva para futuras expansiones, vías expeditas, ferrocarril y aeropuerto, así como también una conexión terrestre con el eje atlántico. Con ello, la ciudad de Valparaíso recuperaría su litoral y su destino perdido por tantos años.

Frente a lo planteado por T2 la presente investigación plantea que en la actualidad los puertos tienen dársenas con resguardo artificial de olas, corrientes y temporales y que, por ello, las empresas marítimas optan por aquellos puertos que ofrecen seguridad y confiabilidad de atención en plazos normales.

Como se ha mostrado aquí, los puertos del mundo han derribado sus muros y se han abierto a la ciudad, mientras que EPV está haciendo lo opuesto en Valparaíso, convirtiendo la extensión total de su borde costero en una industria y en un retail que ese vislumbra sepultará para siempre su mayor espacio público y su destino marítimo. Andueza y Aravena (2013) señalan que EPV tiene poder absoluto sobre el borde costero, pero Lindón plantea que "difícilmente un territorio puede ser comprendido solo desde lo material: también es necesario introducir lo inmaterial, ya lo llamemos cultural, social, o, mejor aún, subjetividad social" (Lindón, 2007, p. 219).

En la misma línea Paquot consigna que atender a otros criterios no solamente materiales "evitaría intervenciones inadecuadas, inhospitalarias, brutales, anodinas o sin cualidad y estandarización que, desgraciadamente, se multiplican desenfrenadamente" (Paquot, 2009, p. 98-99).

El desplazamiento del programa y ubicación del T2 a la poza de abrigo, mediante un espigón protegido por el molo es, a juicio de la presente investigación, una buena salida para la crisis planteada, ya que representa la máxima capacidad portuaria que se podría contener, sin alterar gravemente la ciudad.

Lo anterior permitiría recuperar el litoral de Valparaíso para el espacio urbano en el concepto de maritorio, convirtiendo el agua en un elemento de conformación urbana para la ciudad. El borde costero sería el primer elemento urbano estructurador de las circulaciones por tierra, agua y mar, incorporando los cerros al borde y al plan. 


\section{Referencias}

Andueza, P. y Aravena, P. (2013). Valparaíso reclamado. Valparaíso: Edición Perseo.

Álvarez, L., Silva, L., y Soto, M. (2009). Dimensión espacial de la movilidad cotidiana universitaria: el caso del gran Valparaíso. Revista INVI, 24(65), 19-77. http://dx.doi.org/10.4067/S071883582009000100002

Álvarez, L. (1996). Análisis socioespacial de la pobreza en la región de Valparaíso. Revista Geográfica de Valparaíso, 28. Recuperado de http://geografiapucv.cl/revista-geografica-devalparaiso/

Baeza, A., Vial, J., Uribe, J., e Ivelic, B. (1991). Renovación del estero de Viña del Mar. Revista CA, 63.

Cruz, A. (1954). Estudio urbanístico para una población obrera en Achupallas. Revista Anales, 1, 243.

Cruz, A. y lommi, G. (1970). Para un punto de vista Latinoamericano del Océano Pacífico. Revista de Estudios del Pacífico, 2, 7-27. Recuperado de http://www.scielo.cl/pdf/arq/n73/art03.pdf

Deney, E. (2011). Rambla urbano-marítima para Concón. Recuperado de http://www.ead.pucv.cl/estudiosavanzados/magister-nautico-y-maritimo/tesis-demagister/

Echeverri, A., Texido, A., Undurraga, G., Ruiz, M., Carroza, M., Elizalde, T., y Donoso, P. (2016). Valparaíso y su borde costero: oportunidad o espejismo. Santiago: Sa Cabana Editorial.

Etulain, J. (2008). Gestión promocional o privatización de la gestión urbanística? Proyecto Urbano Puerto Madero, Buenos Aires-Argentina. Bitácora, 1(12), 171-184.

Figueroa, C. (2010). Parque del juego y el deporte en el Aconcagua (tesis inédita).

Ivelic, B. y Baixas, J. (1985). Nuestra latitud Patagonia. Revista CA, 40.

Ivelic, B. y Vásquez, P. (2014). Parque de mar Puerto Barón. Revista Márgenes 11(14), 94-107. Recuperado de

http://revistas.uv.cl/index.php/margenes/article/dow nload/319/286

Janoschka, M. (2002). El nuevo modelo de la ciudad latinoamericana: fragmentación y privatización. EURE, 28(85), 11-20. https://doi.org/10.4067/s0250$\underline{71612002008500002}$
Lindón, A. (2007). La construcción social de los paisajes invisibles del miedo. En J. Nogué (Ed.), La construcción social del paisaje (pp.219-242). Madrid: Editorial Biblioteca Nueva S.L.

Miranda, A. (2016). Parque Puerto Valparaíso (tesis inédita).

Mega Structures Boston Big Dig, documentary (2016). Recuperado de https://www.youtube.com/watch?v=m03PhUdfVUk

Mansilla Quiñones, P. y Fuenzalida Díaz, M. (2010). Procesos de desarrollo urbano-regional y exclusión territorial: nuevas formas de urbanización en el área metropolitana de Valparaíso. Estudio de caso ciudad de Curauma. Revista INVI, 25(69), 103-123. https://doi.org/10.4067/s0718-83582010000200003

Mashini, D. (2012). Como hacer ciudad: El Malecón de Guayaquil. Recuperado de http://www.plataformaurbana.cl/archive/2012/02/0 6/como-hacer-ciudad-el-malecon-de-guayaquil/

Paquot, T. (2009). L'espace public. Paris: La découverte.

Santa María, I. (1988). Un proyecto alternativo para el desarrollo urbano regional de Valparaíso. EURE, 14(43), 79-89. https://www.eure.cl/index.php/eure/article/downloa d/994/105

Sánchez, J. (1971). Maritorio de los archipiélagos de la Patagonia Occidental. Viña del Mar: Edición TIG.

Soza, A. (2010). Puerto en aguas interiores protegida, Aconcagua. Viña del Mar: Edición TIG.

Torrez, C. (2013). Parque deportivo náutico en la desembocadura del río Aconcagua. Viña del Mar: Edición TIG.

Vergara, R. y Foulquier, E. (2012) Marimitidad en Barranquillas: etapas del desarrollo urbano y su relación con el puerto. Investigación y Desarrollo, 20(1), 02-31.

Vergara-Constela, C. y Casellas, A. (2016). Políticas estatales y transformación urbana: Hacia un proceso de gentrificación en Valparaíso Chile? EURE, 42(126), 123-144. https://doi.org/10.4067/s025071612016000200006

Vásquez, P. (2015). Parque de mar puerto Barón. Viña del Mar: Edición TIG. 